\title{
Early Determinants of Mortality in Hospitalized COVID-19 Patients in the Eastern Province of Saudi Arabia
}

\author{
Khalid Aziz Ansari', Marwan Jabr Alwazzeh², Feras Ahmed Alkuwaiti ${ }^{2}$, Faraz Ahmed Farooqi ${ }^{3}$, \\ Noor Al Khathlan (D)', Hussain Almutawah', Mustafa Alahmed', Hussain Alfaraj', Ahmed Aljarrash', \\ Jaffar Almadhary', Sarah Alwarthan ${ }^{2}$, Ahmed Mohammed Alsahlawi², Abdullah Bandar Almashouf ${ }^{2}$, \\ Moammer Alqasim ${ }^{2}$, Elaf Alkuwaiti ${ }^{4}$ \\ 'Department of Respiratory Care, College of Applied Medical Science, Imam Abdulrahman Bin Faisal University, Dammam, Saudi Arabia; \\ ${ }^{2}$ Department of Internal Medicine, College of Medicine, King Fahd Hospital of the University, Imam Abdulrahman Bin Faisal University, Dammam, \\ Saudi Arabia; ${ }^{3}$ Department of Dental Education, College of Dentistry, Imam Abdulrahman Bin Faisal University, Dammam, Saudi Arabia; ${ }^{4}$ College of \\ Dentistry, Imam Abdulrahman Bin Faisal University, Dammam, Saudi Arabia
}

Correspondence: Khalid Aziz Ansari, Email kaansari@iau.edu.sa

Purpose: This study investigated the clinical determinants of mortality in hospitalized patients infected with COVID-19.

Patients and Methods: A retrospective multicenter large cohort of COVID-19 patients hospitalized between March 2020 and February 2021. We included patients admitted with a confirmed COVID-19 infection with positive COVID-19 through real-time polymerase chain reaction (RT-PCR). SPSS version 25.0 (Armonk, NY: IBM Corp.) was used to analyze the data.

Results: Among the study participants $(\mathrm{n}=1444)$, the mean age of the population was $49.22 \pm 17.69$ years, of which $63.9 \%$ were males $(\mathrm{n}=924)$. Overall, the mean age for non-survivors was $55.65 \pm 16.41$ years and the length of ICU stay was $13.95 \pm 12.4$ years. The most common comorbidity among the study subjects was hypertension (HTN) (32.7\%), followed by cardiovascular disease (CVD) (10.7\%). Patients who were mechanically ventilated (MV) had higher mortality than those who did not require MV ( $p<0.001$ ).

Conclusion: Our study concluded that old age, the presence of underlying cardiovascular conditions, an abnormal WBC count (leukopenia or leukocytosis), and abnormal blood urea nitrogen (BUN) levels are among the independent predictors of mortality in the Saudi population. These findings may guide health care providers to manage COVID-19 patients more effectively with better outcomes.

Keywords: COVID, predictors, KSA, mortality, healthcare

\section{Introduction}

Coronavirus disease 2019 (COVID-19) is an infectious disease. A large number of infected people with COVID-19 will suffer from mild-to-moderate symptoms. ${ }^{1,2}$ COVID-19 has been spreading rapidly worldwide. The massive increase in the number of infected people has led to the depletion of resources and a considerable burden on the health sector. ${ }^{3}$ In addition, the COVID-19 crisis has also influenced mortality around the world, affecting hundreds of millions of people. ${ }^{4}$

Studies showed that COVID-19 patients presented with a range of symptoms and clinical findings. Despite the emergence of newer COVID variants such as Delta and Omicron due to viral mutations, ${ }^{5-7}$ the most common clinical symptoms are fever, a dry cough, fatigue, hypoxemia associated with pneumonia, and dyspnea. Less common symptoms include headache, dizziness, abdominal pain, nausea, and vomiting. According to computed tomography (CT) findings, the most frequent findings are a ground-glass appearance or a bilateral consolidation in the peripheral lower lung field. ${ }^{8-13}$

Many associated predictors that are related to health outcomes in patients with COVID 19 infections have been identified. Among these predictors, comorbidity, advanced age, male gender and laboratory biomarkers were among the commonest predictors of severity and mortality in patients with COVID 19 infections. ${ }^{3,10,14-21}$ Some studies have suggested that mortality is higher in Asian and black ethnicities as compared to white and non-Asian backgrounds. ${ }^{22}$ 
Consequently, these predictors are very crucial for the Saudi population because over $30 \%$ of the population is considered older aged and over $57 \%$ of the population are male. ${ }^{23}$ This study will explore the association of gender and age with patients who are hospitalized with COVID-19 infection in Saudi Arabia.

In addition to demographics, various clinical parameters such as comorbidities have been identified as predictors of health outcomes in patients hospitalized with COVID-19 in Saudi Arabia and elsewhere. ${ }^{10,13-17,24-28}$ The most common comorbidities were found to be hypertension, diabetes mellitus, pulmonary hypertension, pulmonary embolism, history of coronary artery disease, end-stage renal disease (or chronic kidney disease), hypothyroidism, active cancer, refractory/relapsed lymphoma and hematological malignancy. This will be interesting to explore in our population because it is estimated that there are more than 1.7 million Saudi individuals who have diabetes mellitus and 5 million who have hypertension. ${ }^{29,30}$

More recently, some research also examined the relationship of laboratory parameters with COVID-19.,10 These include procalcitonin (PCT), lactic acid, circulating lymphocytes (LYM) percentage, viral load (ORF1ab Ct), D-dimer levels, C-reactive protein (CRP), and serum lactate dehydrogenase (LDH). LYM percentage is considered the most sensitive and reliable in discriminating critically ill, severe, and moderate patients as well as between survivors and nonsurvivors. ${ }^{3,10,16,31,32}$ However, there are no conclusive data available in relation to the laboratory markers and health outcomes in Saudi patients with COVID-19 and this study will further investigate this area.

Therefore, the present study will investigate the physiological and clinical determinants of health outcomes, particularly mortality, in patients hospitalized with a COVID-19 infection in the eastern province of the KSA.

\section{Materials and Methods}

\section{Study Design and Participants}

This was a retrospective multicenter cohort study of 1444 identified COVID-19 patients. All patients enrolled in this study were confirmed positive for COVID-19 through real-time RT-PCR obtained through nasopharyngeal or oropharyngeal swabs between March 2020 and February 2021. Our focus in data gathering was on determinants of health outcomes, particularly mortality, and the length of hospital stay.

\section{Data Collection}

Data were obtained from soft medical records using the medical record number for each patient admitted to Al-Qatif Central Hospital and King Fahad Hospital of the University using a Microsoft Excel form designed by the research team to organize the extracted data. The data obtained included patients' demographics, comorbidities, diagnostics workup, routine lab tests done to assess disease status and severity, duration of hospital stay including ICU admission, need of MV, and records of discharge or death. The data were divided into two main categories for comparison purposes, ie, alive and dead. Furthermore, to assess severity, the data was further classified into "mild to moderate", "severe" and "critical" based on parameters defined elsewhere. ${ }^{2}$

\section{Ethics}

Ethical approval was obtained from the Institutional Review Board (IRB) at Imam Abdulrahman Bin Faisal University (IAU) and both hospitals. The institutional review board/ethics committee waived the need for informed consent. Researchers ensured that all personal information of the patients obtained from the hospital was kept confidential in a secured password protected folder and was only being used for data analysis purposes. Our research was carried out in accordance with the Declaration of Helsinki of the World Medical Association.

\section{Statistical Analysis}

Data was initially recorded in Excel and cleaned. Then, it was imported to SPSS (statistical Package for Social sciences) version 25.0, IBM, USA, for analysis. Missing values were treated with assigned codes if the records were found. Patients with $70 \%$ of missing data were removed. The distribution of the data set were examined using Shapiro-Wilk Test. Total counts (frequency), percentages, mean, and standard deviations were calculated as a part of descriptive statistics for demographical characteristics of patients. An independent sample $t$-test/Mann Whitney $U$-test was performed for continued variables and Chi-squared /Fisher exact test was used for categorical associations where 
appropriate. Univariate and multivariate logistics regression models were made to identify the independent and combined factors associated with the mortality of COVID-19 patients, OR, 95\% CI and p values were reported. Kaplan-Meier survival curves (KMSC) were drawn to check the survival probabilities from the time of admission in ICU to the followup. Log-rank was used to compare the groups. A p-value less than 0.05 were considered statistically significant.

\section{Results}

A total of 1444 patients were included, out of which 924 (63.9\%) were males and 75\% were Saudi citizens. We classified our sample into four age categories: 0-40 years old (y/o) (413, 28.6\%), 41-55 y/o (494, 34.2\%), 56-70 y/o (381, 26.3\%), greater than $70 \mathrm{y} / \mathrm{o}(157,10.8 \%)$. Out of 1444 patients, $266(18 \%)$ were admitted to ICU and $99(6.8 \%)$ were mechanically ventilated. The majority of the sample had at least one comorbidity which included $473(32.7 \%)$ with hypertension (HTN), 85 (5.8\%) with chronic kidney disease (CKD), 155 (10.7\%) with cardiovascular disease (CVD), 28 (1.9\%) with gastrointestinal (GI) disease and 202 (14\%) with diabetes mellitus (DM) (Table 1).

Patients were divided into two groups, survival (alive) and non-survivable (dead) with demographic characteristics in Table 2. In terms of mortality rate, patients who were less than 40 years old had a mortality rate of $6 \%$, between 41 and

Table I The Demographics of the Study Population

\begin{tabular}{|c|c|c|c|}
\hline \multicolumn{2}{|l|}{ Demographic Variables } & \multirow{2}{*}{$\frac{\text { No of Study Subjects (n) }}{413}$} & \multirow{2}{*}{$\begin{array}{c}\text { Percentage } \\
28.6 \%\end{array}$} \\
\hline Age Categories & Less than 40 & & \\
\hline & $4 I-55$ & 494 & $34.2 \%$ \\
\hline & $56-70$ & 381 & $26.3 \%$ \\
\hline & Greater than 70 & 157 & $10.8 \%$ \\
\hline \multirow[t]{2}{*}{ Gender } & Male & 924 & $63.99 \%$ \\
\hline & Female & 520 & 39.01 \\
\hline \multirow[t]{2}{*}{ Ethnicity } & Saudi & 1089 & $75.4 \%$ \\
\hline & Non-Saudi & 356 & $24.6 \%$ \\
\hline \multirow[t]{2}{*}{ Hypertension (HTN) } & No & 971 & $76.2 \%$ \\
\hline & Yes & 473 & $32.8 \%$ \\
\hline \multirow{2}{*}{$\begin{array}{l}\text { Chronic Kidney disease } \\
\text { (CKD) }\end{array}$} & No & 1359 & $94.11 \%$ \\
\hline & Yes & 85 & $5.9 \%$ \\
\hline \multirow{2}{*}{$\begin{array}{l}\text { Cardiovascular Disease } \\
\text { (CVD) }\end{array}$} & No & 1294 & $89.6 \%$ \\
\hline & Yes & 155 & $10.4 \%$ \\
\hline \multirow[t]{2}{*}{ Diabetes } & No & 260 & $18 \%$ \\
\hline & Yes & 202 & $14 \%$ \\
\hline \multirow{2}{*}{$\begin{array}{l}\text { Gastrointestinal (GI) } \\
\text { disorder }\end{array}$} & No & 1416 & $98.06 \%$ \\
\hline & Yes & 28 & $1.9 \%$ \\
\hline \multirow[t]{2}{*}{ Need for ICU admission } & No & 1178 & $81.5 \%$ \\
\hline & Yes & 266 & $14.5 \%$ \\
\hline \multirow{2}{*}{$\begin{array}{l}\text { Need for mechanical } \\
\text { ventilation }\end{array}$} & No & 1345 & $93.1 \%$ \\
\hline & Yes & 99 & $6.9 \%$ \\
\hline
\end{tabular}


Table 2 Comparison Between Survivors and Nonsurvivors for COVID 19 Patients

\begin{tabular}{|c|c|c|c|c|}
\hline \multicolumn{2}{|c|}{ Demographic Variables } & \multirow{2}{*}{$\begin{array}{r}\text { Alive n (\%) } \\
387(94)\end{array}$} & \multirow{2}{*}{$\frac{\text { Dead n (\%) }}{26(6 \%)}$} & \multirow{2}{*}{$\frac{\text { P-value }}{<0.001^{*}}$} \\
\hline Age Categories & Less than 40 & & & \\
\hline & $4 I-55$ & $444(90)$ & $50(10)$ & \\
\hline & $56-70$ & $324(85)$ & $57(15)$ & \\
\hline & Greater than 70 & $132(84)$ & $25(16)$ & \\
\hline \multirow[t]{2}{*}{ Gender } & Male & $817(88)$ & $107(12)$ & \multirow[t]{2}{*}{0.172} \\
\hline & Female & $469(90)$ & $5 I(10)$ & \\
\hline \multirow[t]{2}{*}{ Nationality } & Saudi & $976(90)$ & $113(10)$ & \multirow[t]{2}{*}{0.138} \\
\hline & Non-Saudi & $3 I I(87)$ & $45(13)$ & \\
\hline \multirow[t]{2}{*}{ HTN } & No & $877(91)$ & $90(9)$ & \multirow[t]{2}{*}{$0.007^{*}$} \\
\hline & Yes & $406(86)$ & $67(14)$ & \\
\hline \multirow[t]{2}{*}{ CKD } & No & $1216(89)$ & $144(11)$ & \multirow[t]{2}{*}{0.105} \\
\hline & Yes & $7 I(83)$ & $14(17)$ & \\
\hline \multirow[t]{2}{*}{ Cardiovascular Disease } & No & $1156(90)$ & $124(10)$ & \multirow[t]{2}{*}{$<0.00 I^{*}$} \\
\hline & Yes & $124(80)$ & $3 I(20)$ & \\
\hline \multirow[t]{2}{*}{ GI Disease } & No & $1170(89)$ & $140(11)$ & \multirow[t]{2}{*}{0.370} \\
\hline & Yes & II (87) & $17(13)$ & \\
\hline \multirow{2}{*}{$\begin{array}{l}\text { Need for ICU } \\
\text { admission }\end{array}$} & No & $1166(99)$ & $14(1)$ & \multirow[t]{2}{*}{$<0.001 *$} \\
\hline & Yes & $116(45)$ & $144(54)$ & \\
\hline \multirow[t]{2}{*}{ Need for MV } & No & $359(98)$ & $5(2)$ & \multirow[t]{2}{*}{$<0.00 I^{\prime}$} \\
\hline & Yes & $43(43)$ & $56(57)$ & \\
\hline \multicolumn{2}{|l|}{ Age in Years } & $48.43 \pm 17.7$ & $55.65 \pm 16.41$ & $<0.00 I^{*}$ \\
\hline \multicolumn{2}{|l|}{ Length of Hospitalization } & $7.90 \pm 8.19$ & $13.95 \pm 12.4$ & $<0.001 *$ \\
\hline \multicolumn{2}{|l|}{ Weight (Kg) } & $67.96 \pm 34.95$ & $76.47 \pm 14.68$ & 0.14 \\
\hline
\end{tabular}

Note: *statistically significant at 0.05 .

$55 \mathrm{y} / \mathrm{o}$ had a rate of $10 \%$, between 56 and $70 \mathrm{y} / \mathrm{o}$ had a rate of $15 \%$ and greater than $70 \mathrm{y} / \mathrm{o}$ had a rate of $16 \%(\mathrm{p}<0.001)$. The mortality of patients who were admitted to ICU was $56 \%(\mathrm{p}<0.05)$ compared to those who were not admitted to ICU. Similarly, patients who required mechanical ventilation support was $57 \%(\mathrm{p}>0.05)$ compared to those who did not need any artificial support. Regarding comorbidities, patients with HTN had a mortality rate of $14 \%$ ( $>>0.05)$, out of which $17 \%$ had CKD ( $p=0.105), 20 \%$ had CVD $(p>0.05)$ and $13 \%$ had GI conditions $(p=0.37)$. Additionally, the mortality rate was the same between Saudi and non-Saudi patients (90\% vs $87 \%)$, which were not statistically significant $(\mathrm{p}=0.138)$. COVID-19 patients who survived were younger $(48.43 \pm 17.7)(\mathrm{p}<0.001)$. Furthermore, there was a significant difference in the duration of hospitalization (days) between the alive and discharged patients and patients who died (8 days vs 14 days; $\mathrm{p}<0.001$ ) (Table 2).

Laboratory findings showed that neutrophil count was $40 \%$ higher among the patients who died as compared to those who survived ( $\mathrm{p}=0.028$; Table 3$)$. Additionally, BUN levels were abnormally high in deceased patients when compared with those who recovered (51\% vs $36 \% ; \mathrm{p}=0.003)$. In addition, abnormal levels of Sodium (Na), Chloride $(\mathrm{Cl})$, LDH, 
Table 3 Lab Findings in Alive and Dead Patients

\begin{tabular}{|c|c|c|c|c|}
\hline \multicolumn{2}{|l|}{ Lab Results } & \multirow{2}{*}{$\begin{array}{r}\text { Alive n (\%) } \\
834(90)\end{array}$} & \multirow{2}{*}{$\begin{array}{r}\text { Dead n (\%) } \\
92(10)\end{array}$} & \multirow{2}{*}{$\frac{\text { P-value }}{0.11}$} \\
\hline WBC & Normal & & & \\
\hline & Abnormal & $439(87)$ & $64(13)$ & \\
\hline \multirow[t]{2}{*}{ Hemoglobin $(\mathrm{Hg})$} & Normal & $455(90)$ & $48(10)$ & \multirow[t]{2}{*}{0.248} \\
\hline & Abnormal & $818(88)$ & $108(12)$ & \\
\hline \multirow[t]{2}{*}{ PLT } & Normal & $306(86)$ & $50(14)$ & \multirow[t]{2}{*}{0.415} \\
\hline & Abnormal & $96(90)$ & $I I(I 0)$ & \\
\hline \multirow[t]{2}{*}{ Neutrophil } & Normal & $847(91)$ & $86(9)$ & \multirow[t]{2}{*}{0.028} \\
\hline & Abnormal & $372(87)$ & $57(13)$ & \\
\hline \multirow[t]{2}{*}{ Lymphocyte } & Normal & $718(90)$ & $79(10)$ & \multirow[t]{2}{*}{0.42} \\
\hline & Abnormal & $502(89)$ & $64(11)$ & \\
\hline \multirow[t]{2}{*}{ BUN } & Normal & $459(86)$ & $77(14)$ & \multirow[t]{2}{*}{$0.003 *$} \\
\hline & Abnormal & 789(9I) & $79(9)$ & \\
\hline \multirow[t]{2}{*}{ Creatinine } & Normal & 735(89) & $87(\mathrm{II})$ & \multirow[t]{2}{*}{0.439} \\
\hline & Abnormal & $511(88)$ & $69(12)$ & \\
\hline \multirow[t]{2}{*}{$\mathrm{Na}$} & Normal & 793(9I) & $77(9)$ & \multirow[t]{2}{*}{$0.002^{*}$} \\
\hline & Abnormal & $454(85)$ & $79(15)$ & \\
\hline \multirow[t]{2}{*}{ K } & Normal & 1049(89) & $125(11)$ & \multirow[t]{2}{*}{0.244} \\
\hline & Abnormal & 193(87) & $30(13)$ & \\
\hline \multirow[t]{2}{*}{$\mathrm{Cl}$} & Normal & $906(91)$ & $94(9)$ & \multirow[t]{2}{*}{$0.002 *$} \\
\hline & Abnormal & $340(84)$ & $62(16)$ & \\
\hline \multirow[t]{2}{*}{ LDH } & Normal & $228(95)$ & $\mathrm{II}(5)$ & \multirow[t]{2}{*}{$<0.001 *$} \\
\hline & Abnormal & $898(87)$ & $137(13)$ & \\
\hline \multirow[t]{2}{*}{ ESR } & Normal & 163(91) & $16(9)$ & \multirow[t]{2}{*}{$0.048 *$} \\
\hline & Abnormal & $58 I(84)$ & $108(16)$ & \\
\hline \multirow[t]{2}{*}{ CRP } & Normal & $54(96)$ & 2(4) & \multirow[t]{2}{*}{$0.037^{*}$} \\
\hline & Abnormal & $884(87)$ & $133(13)$ & \\
\hline \multirow[t]{2}{*}{ Ferritin } & Normal & $182(93)$ & $13(7)$ & \multirow[t]{2}{*}{$0.004 *$} \\
\hline & Abnormal & $795(86)$ & $128(14)$ & \\
\hline PT & Normal & 273(89) & $33(11)$ & $0.042^{*}$ \\
\hline & Abnormal & $129(82)$ & $28(18)$ & \\
\hline PTT & Normal & $257(9 I)$ & $25(9)$ & $<0.001 *$ \\
\hline & Abnormal & $145(80)$ & $36(20)$ & \\
\hline
\end{tabular}

Note: *statistically significant at 0.05 . 
ESR (Erythrocyte Sedimentation Rate), CRP, ProthromBin Time (PT), Partial Thromboplastin Time (PTT) and ferritin were also found to be significantly higher in patients who died than in those who survived $(p<0.05)$ (Table 3 ).

Regarding COVID-19 severity among the patients who died, $7 \%$ had mild-to-moderate symptoms, $25 \%$ experienced severe symptoms and almost $63 \%$ developed critical illnesses such as multi organ failure and altered consciousness. Out of the 1444 patients, $214(14.8 \%)$ developed pneumonia, 108 (7.4\%) required supplemental oxygen, $110(7.6 \%)$ had respiratory rate (RR) greater than 30 breaths per minute (bpm), $162(11.2 \%)$ had oxygen saturation (SpO2) less than 93\%, 93 (6.4\%) had lung infiltration (>50\% of lung fields), $42(2.9 \%)$ had a PaO2/FiO2 ratio $(<300), 108(7.4 \%)$ had acute respiratory distress syndrome (ARDS), 66 (4.5\%) sepsis, 38 (2.6\%) loss of consciousness (LOC), and 25 (1.7\%) multi-organ failure (Table 4).

All significant predictors from univariate regression (Table 5) were then analyzed in multivariate logistics regression models (Table 6). All predictors were introduced step-wise to get the best predictors of COVID-19 mortality. After adjusting for all variables, our logistics regression model number 3 included age (in years) (1.07, 95\% CI 1.007-1.028), presence of cardiac disease (1.68, 95\% CI 1.065-2.674), WBC counts (Neutrophils) (1.02, $95 \%$ CI $1.001-1.039, \mathrm{p}=0.02)$, and BUN levels $(1.017,95 \%$ CI $1.007-1.027, \mathrm{p}<0.001)$ as the best predictors of COVID related mortality.

Table 4 The Distribution of Severity Between Alive and Dead Subjects

\begin{tabular}{|c|c|c|c|c|c|}
\hline \multicolumn{3}{|l|}{ Variables } & \multirow{2}{*}{$\begin{array}{r}\text { Alive n (\%) } \\
1073(89)\end{array}$} & \multirow{2}{*}{$\frac{\text { Dead n (\%) }}{129(10)}$} & \multirow{2}{*}{$\frac{\text { p-value }}{0.552}$} \\
\hline \multirow{4}{*}{$\begin{array}{l}\text { Mild/to/ } \\
\text { Moderate }\end{array}$} & \multirow[t]{2}{*}{ No pneumonia on CXR } & No & & & \\
\hline & & Yes & $188(87)$ & $26(13)$ & \\
\hline & \multirow[t]{2}{*}{ Supplemental Oxygen } & No & 295(83) & $60(17)$ & \multirow[t]{2}{*}{$<0.001 *$} \\
\hline & & Yes & 107(99) & $\mathrm{I}(\mathrm{I})$ & \\
\hline \multirow[t]{8}{*}{ Severe } & \multirow[t]{2}{*}{$\mathrm{RR}>30 \mathrm{mint}$} & No & $319(90)$ & $34(10)$ & \multirow[t]{2}{*}{$<0.001 *$} \\
\hline & & Yes & $83(75)$ & $27(25)$ & \\
\hline & \multirow[t]{2}{*}{$\mathrm{SpO} 2<93 \% \mathrm{RA}$} & No & $269(89)$ & $32(10)$ & \multirow[t]{2}{*}{$0.03 I^{*}$} \\
\hline & & Yes & $133(82)$ & $29(18)$ & \\
\hline & \multirow[t]{2}{*}{$\mathrm{PaO} 2 / \mathrm{FiO} 2<300$} & No & $382(91)$ & 39(9) & \multirow[t]{2}{*}{$<0.001 *$} \\
\hline & & Yes & $20(48)$ & $22(52)$ & \\
\hline & \multirow{2}{*}{$\begin{array}{l}\text { Lung infiltrates }>50 \% \text { of lung field within } \\
24-48 \text { hours }\end{array}$} & No & $324(87)$ & $46(13)$ & \multirow[t]{2}{*}{0.391} \\
\hline & & Yes & $78(84)$ & $15(16)$ & \\
\hline \multirow[t]{8}{*}{ Critical } & \multirow[t]{2}{*}{ ARDS } & No & $1224(92)$ & $109(8)$ & \multirow[t]{2}{*}{$<0.001 *$} \\
\hline & & Yes & $60(55)$ & $48(45)$ & \\
\hline & \multirow[t]{2}{*}{ Sepsis } & No & $1250(9 \mid)$ & $125(9)$ & \multirow[t]{2}{*}{$<0.00 I^{*}$} \\
\hline & & Yes & $34(52)$ & $32(48)$ & \\
\hline & \multirow[t]{2}{*}{ Altered LOC } & No & $388(92)$ & $35(8)$ & \multirow[t]{2}{*}{$<0.001 *$} \\
\hline & & Yes & $13(34)$ & $25(66)$ & \\
\hline & \multirow[t]{2}{*}{ Multi-organ failure } & No & $400(92)$ & $37(8)$ & \multirow[t]{2}{*}{$<0.001 *$} \\
\hline & & Yes & $2(8)$ & $23(92)$ & \\
\hline
\end{tabular}

Note: *statistically significant at 0.05 . 
Table 5 Univariate Regression Variables

\begin{tabular}{|c|c|c|}
\hline Variable & OR (95\% Cl) & p-value \\
\hline Age & $0.024(1.015-1.035)$ & $<0.001 *$ \\
\hline HTN & $1.608(1.148-2.253)$ & $0.006^{*}$ \\
\hline CVD & $2.331(1.509-3.601)$ & $<0.001 *$ \\
\hline WBC value & $1.023(1.002-1.045)$ & $0.029 *$ \\
\hline Lymphocyte & $0.832(0.693-0.998)$ & $0.047^{*}$ \\
\hline BUN & $1.022(1.012-1.033)$ & $<0.001 *$ \\
\hline LDH & $1.002(1.001-1.002)$ & $<0.001 *$ \\
\hline ESR & $1.01(1.004-1.017)$ & $0.003^{*}$ \\
\hline Oxygen (NIV) & $0.046(0.006-0.336)$ & $0.002^{*}$ \\
\hline $\mathrm{RR}>30 \mathrm{bpm}$ & $3.052(1.743-5.343)$ & $<0.001 *$ \\
\hline $\mathrm{SpO} 2$ & $1.833(1.064-3.157)$ & $0.029 *$ \\
\hline Lung infiltrates & $10.774(5.408-2 \mid .468)$ & $<0.001 *$ \\
\hline ARDS & $8.983(5.861-13.77)$ & $<0.001 *$ \\
\hline Sepsis & $9.412(5.615-15.776)$ & $<0.001 *$ \\
\hline Altered LOC & $21.319(10.028-45.321)$ & $<0.001 *$ \\
\hline Ferritin $>600$ & $3.018(2.066-4.409)$ & $<0.001 *$ \\
\hline Need of MV & $93.507(35.52-246.161)$ & $<0.001 *$ \\
\hline
\end{tabular}

Note: *Statistically significant at 0.05 .

Kaplan-Meier survival analysis (KMSA) for survival rate from an ICU admission until a follow-up showed that patients aged between 40 and 55 years had a higher probability of survival than patients older than 70 years. Figure 1. Whereas other KMSA (Figure 2) demonstrates that a longer need of MV was associated with a higher mortality rate.

\section{Discussion}

In this retrospective multicenter cohort study conducted in the eastern province of Saudi Arabia, we investigated the predictors of mortality among hospitalized patients with COVID-19. Findings of this study showed that the most significant independent predictors that were associated with a higher risk of death in hospitalized COVID 19 patients were as follows: male gender, being elderly (older than 70 years), presence of comorbidities such as hypertension, cardiovascular disease, ARDS or sepsis, admission in the ICU, need for MV, $\mathrm{SpO} 2<93 \%$ on admission, RR $>30 / \mathrm{min}$, need for supplemental oxygen, lung infiltrates $>50 \%$ of the lung field within 24 to 48 hours of admission, loss of consciousness (LOC), abnormal blood levels of neutrophils, lymphocyte, BUN, LDH, ESR, and ferritin. However, when these predictors were combined for further analysis, the present study confirmed that age, cardiac disease and WBC count were the most significant set of predictors of mortality in our population which is consistent with existing findings from other studies worldwide. ${ }^{33-37}$

Arguably, Knight and coworkers $(2020)^{38}$ identified eight important predictors and suggested a model called the $4 \mathrm{C}$ Mortality Score, which includes age, gender, number of comorbidities, respiratory rate, peripheral oxygen saturation, Glasgow coma scale, urea level and $\mathrm{C}$ reactive protein. In the present study, when gender was compared (Table 2), the study results found that male gender was associated with worse outcomes such as mortality and lower recovery rate. Many studies relate this to the higher viral load or exposure of male gender compared to females due to the nature of their 
Table 6 Multivariate Logistic Regression Analysis of COVID-19 Mortality

\begin{tabular}{|c|c|c|}
\hline Models & OR (95\% Cl) & p-value \\
\hline \multicolumn{3}{|l|}{ Model I } \\
\hline Age & $1.021(1.01-1.031)$ & $<0.001 *$ \\
\hline Cardiac Disease & $1.78(I .128-2.8 I)$ & $0.013^{*}$ \\
\hline WBC & $1.022(1.001-1.044)$ & $0.037^{*}$ \\
\hline \multicolumn{3}{|l|}{ Model 2} \\
\hline Age & $1.02(1.008-1.031)$ & $<0.001 *$ \\
\hline Cardiac Disease & $1.887(1.17 \mid-3.039)$ & $0.009 *$ \\
\hline WBC & $1.044(1.017-1.072)$ & $<0.001 *$ \\
\hline Lymphocyte & $0.849(0.703-1.024)$ & 0.087 \\
\hline \multicolumn{3}{|l|}{ Model 3} \\
\hline Age & $1.017(1.007-1.028)$ & $0.002^{*}$ \\
\hline Cardiac Disease & $1.687(1.065-2.674)$ & $0.026^{*}$ \\
\hline WBC Counts & $1.02(1.001-1.039)$ & $0.047^{*}$ \\
\hline Bun level & $1.017(1.007-1.027)$ & $<0.001 *$ \\
\hline \multicolumn{3}{|l|}{ Model 4} \\
\hline Age & $1.02(1.007-1.032)$ & $<0.001 *$ \\
\hline Cardiac Disease & $1.77(1.067-2.938)$ & $0.027^{*}$ \\
\hline WBC & $1.006(0.985-1.028)$ & $0.57 \mathrm{I}$ \\
\hline Bun & $1.014(1.003-1.025)$ & $0.012^{*}$ \\
\hline LDH & $1.002(1.001-1.003)$ & $<0.001 *$ \\
\hline \multicolumn{3}{|l|}{ Model 5} \\
\hline Age & $1.021(1.008-1.034)$ & $0.002^{*}$ \\
\hline Cardiac Disease & $1.433(0.808-2.542)$ & 0.218 \\
\hline WBC & $1.015(0.996-1.034)$ & 0.116 \\
\hline Bun & $1.012(1-1.024)$ & 0.056 \\
\hline Ferritin & $I(I-I)$ & $<0.0018$ \\
\hline \multicolumn{3}{|l|}{ Model 6} \\
\hline Age & $\mathrm{I}(0.982-1.018)$ & 0.973 \\
\hline Cardiac Disease & $1.674(0.815-3.44)$ & 0.161 \\
\hline WBC Counts & $1.005(0.963-1.049)$ & 0.818 \\
\hline Bun & $1.015(1.002-1.028)$ & 0.0238 \\
\hline Lung infiltrates & I.427(0.748-2.72I) & 0.280 \\
\hline
\end{tabular}

Note: *Statistically significant at 0.05 . 


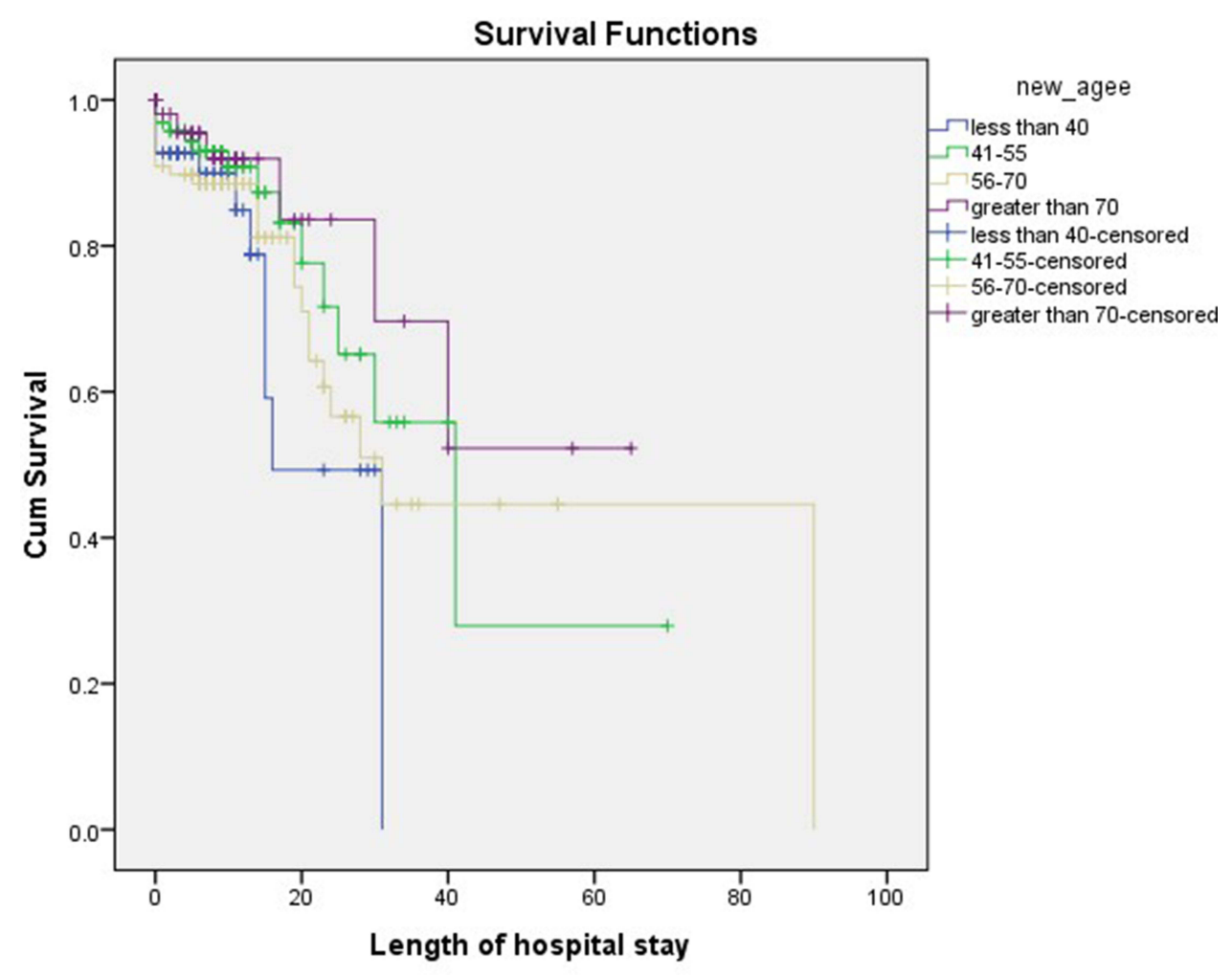

Figure I Kaplan-Meier survival analysis in COVID patients with different age groups.

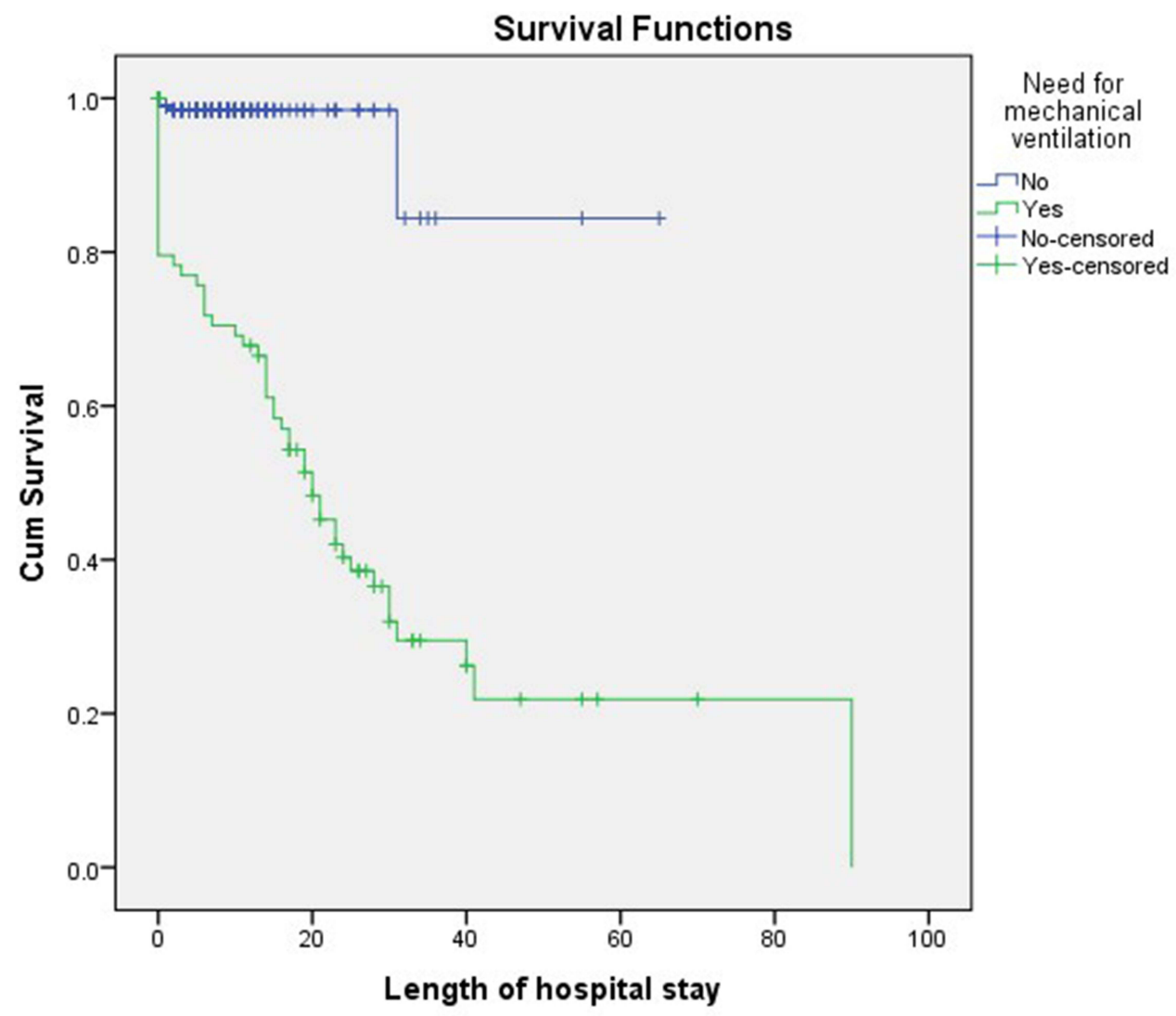

Figure 2 Kaplan-Meier survival analysis in COVID patients with need of MV. 
occupation. ${ }^{3,10,14,15,17,18}$ Furthermore, this may be due to the variation in immunological responses among study subjects in our population. ${ }^{34}$ In addition, it is also indicated that mortality is significantly higher in hypertensive patients than nonhypertensive, which is similar to the findings of previous studies. ${ }^{39-41}$ Taking into account that Angiotensin-converting enzyme (ACE) is a functional receptor for SARS-CoV, the use of renin-angiotensin-aldosterone system inhibitors (RAAS) as antihypertensive was suspected to be deleterious in COVD-19 patients; however, this hypothesis was rejected by further studies. ${ }^{41,42}$ Our findings also emphasize on the role of antihypertensive drugs such as Angiotensin-converting enzyme (ACE) inhibitors and Angiotensin II receptor blockers (ARB) in managing patients with COVID 19 infection. ${ }^{35,39-43}$

In relation to obesity, in 2013, Saudi health interview survey published data showed a high percentage (more than $28 \%$ ) of obesity in the KSA. ${ }^{44}$ In addition, previous research found that obesity is one of the major comorbidities to be considered as it increases the risk of different complications such as DM, liver diseases and cardiovascular diseases. More particularly, severe obesity is found to be an important predictor of COVID-19 outcomes in middleaged patients. ${ }^{36}$ However, our study could not explore BMI or obesity as a predictor because of the lack of data on height and subsequently calculating the body mass index in our population, which we consider one of the major limitations of our study. Therefore, further research is needed in the Saudi population to make a conclusive remark.

In relation to comorbidities other than obesity, our study found that cardiovascular disease and hypertension were among the important predictors of higher mortality rate, which is consistent with previous research findings. ${ }^{13,14,25,26}$ However, Lamure et al found that there is no significant association between hypertension and the mortality rate in COVID-19 patients. ${ }^{37}$ The reason behind this might be related to their limited sample size and the fact that less than half of their study population had hypertension.

Among other factors, the present study also suggests that patients who needed an ICU admission during their hospitalization and/or required MV were having higher severity of the disease and poor prognosis. Furthermore, studies also found that male patients aged $\geq 40$ years old with comorbidities had a higher risk of severe outcomes, particularly diabetes mellitus and hypertension. ${ }^{16,25,42,43}$

The present study found that some blood and serum markers, mainly WBC, BUN, Na, Cl, LDH, CRP, Ferritin, PT, and PTT levels were significantly abnormal in COVID-19 patients when compared with deceased patients. This finding was parallel to findings from previous studies. ${ }^{3,10,16,17,29,30}$ However, there was no single study that found all abovementioned blood and serum levels associated with higher mortality, which may be due to a large sample size with a broad variety of lab results. More importantly, the parameters of our findings are known to be related to sepsis-septic shock, ARDS, multiorgan failure, or related directly to COVID-19. ${ }^{14}$

In relation to COVID-19 severity (Table 4), the need of supplemental oxygen, RR $>30, \mathrm{SpO} 2<93 \%$, lung infiltration, 50\%, ARDS, sepsis, loss of consciousness were significant determinants of mortality in the present study. Our findings are consistent with previous studies. ${ }^{45,46}$

After adjusting for all variables in the logistic regression model (Table 6), we found that age, presence of cardiac disease, WBC counts, and BUN levels were the best predictors of COVID 19 mortality. These findings are consistent with the mortality predictors that found by Di Castelnuovo et $\mathrm{al}^{47}$ in a large cohort of COVID-19 patients admitted to 30 medical centers in Italy.

To explore the predictors of survivors, the Kaplan-Meier survival analysis (KMSA) (Figures 1 and 2) from admission to ICU until the follow-up visit indicated that patients $<40$ to 55 years old had a higher probability to survive than patients older than 70 years. This is consistent with findings from previous studies. ${ }^{48,49}$ Our data also demonstrated that the longer need of MV was associated with a higher mortality rate in our study population (Figure 2), which is similar to previous studies done in other parts of the world..$^{50}$

Several limitations are associated with this study. Firstly, it is a multicenter retrospective study where the data was collected from two different hospitals. For this reason, the raw data provided has little inconsistency in terms of parameters reported in their database, including height, BMI and diabetes, which to some extent limit the opportunity to explore some associations between these important clinical parameters as suggested by other previous studies. ${ }^{16,51}$ Although the clinical parameters and lab values included in the study were sufficient to answer the research hypothesis and the sample size was large enough to analyze and draw a meaningful conclusion, predictors found in this study should be validated in further longitudinal studies. Furthermore, the COVID-19 pandemic is responsible for deaths from other 
causes due to nationwide lockdowns which lead to disruption to health service delivery, interrupted routine immunizations programs, cancelled follow up appointments for patients with various other infectious, non-infectious, acute and chronic illnesses, and shortages of funding for non-COVID-19 services. ${ }^{52,53}$ Therefore, further studies are needed to explore the correct estimation of the indirect effect of the COVID-19 pandemic on mortality from non-COVID causes.

\section{Conclusion}

Our study concluded that old age, presence of underlying cardiovascular conditions, abnormal WBC count (leukopenia or leukocytosis) and abnormal BUN levels are among the independent predictors of mortality in Saudi population. These findings may guide for early triage of COVID-19 patients indicating those at high risk of developing severe disease and help health care providers to manage COVID-19 patients more effectively with better outcomes. The use of validated COVID-19 severity determinants or scores will also lead to better allocation of restricted health care resources in the case of an overwhelming increase of hospitalized patients during COVID-19 pandemic waves. Nevertheless, further studies are needed to validate our findings on a larger cohort of patients as well as to investigate the relationship between age, mortality and body mass index in patients hospitalized with COVID-19. In addition, researchers should further explore the impact of diabetes on COVID-19 outcomes in the Saudi population and elucidate possible differences of COVID-19 severity determinants according to the population characteristics and geographical area.

\section{Disclosure}

The authors report no conflicts of interest in this work.

\section{References}

1. World Health Organization. Coronavirus overview; 2020. Available from: https://www.who.int/health-topics/coronavirus\#tab=tab_1. Accessed February 1, 2022.

2. Gandhi RT, Lynch JB, Del Rio. C. Mild or moderate Covid-19. NEJM. 2020;383(18):1757-1766. doi:10.1056/NEJMcp2009249

3. Tan L, Kang X, Ji X, et al. Validation of predictors of disease severity and outcomes in COVID-19 patients: a descriptive and retrospective study. Med. 2020;1(1):128-138.e3. doi:10.1016/j.medj.2020.05.002

4. World Health Organization. Impact of COVID-19 on people's livelihoods, their health and our food systems. Joint statement by ILO, FAO, IFAD and WHO; October 13, 2020. Available from: https://www.who.int/news/item/13-10-2020-impact-of-covid-19-on-people's-livelihoods-their-healthand-our-food-systems. Accessed February 1, 2022.

5. Dougherty K, Mannell M, Naqvi O, Matson D, Stone J. SARS-CoV-2 B.1.617.2 (Delta) variant COVID-19 outbreak associated with a gymnastics facility-Oklahoma, April-May 2021. MMWR Morb Mortal Wkly Rep. 2021;70(28):1004-1007. doi:10.15585/mmwr.mm7028e2

6. World Health Organization. Update on omicron; November, 2021. Available from: https://www.who.int/news/item/28-11-2021-update-on-omicron. Accessed November. 29, 2021.

7. Centers for Disease Control and Prevention. Science brief: omicron (B.1.1.529) variant; December 3, 2021. Available from: https://www.cdc.gov/ coronavirus/2019-ncov/science/science-briefs/scientific-brief-omicron-variant.html. Accessed December 3, 2021.

8. Wang D, Hu B, Hu C, et al. Clinical characteristics of 138 hospitalized patients with 2019 novel coronavirus-infected pneumonia in Wuhan, China. JAMA. 2020;323(11):1061-1069. doi:10.1001/jama.2020.1585

9. Duan J, Wang X, Chi J, et al. Correlation between the variables collected at admission and progression to severe cases during hospitalization among patients with COVID-19 in Chongqing. J Med Virol. 2020;92(11):2616-2622. doi:10.1002/jmv.26082

10. Alharthy A, Aletreby W, Faqihi F, et al. Clinical characteristics and predictors of 28-day mortality in 352 critically ill patients with COVID-19: a retrospective study. J Epidemiol Glob Health. 2021;11(11):98. doi:10.2991/jegh.k.200928.001

11. Wong HYF, Lam HYS, Fong AH, et al. Frequency and distribution of chest radiographic findings in patients positive for COVID-19. Radiology. 2020;296(2):E72-E78. doi:10.1148/radiol.2020201160

12. Chung M, Bernheim A, Mei X, et al. CT imaging features of 2019 novel Coronavirus (2019-nCoV). Radiology. 2020;295(1):202-207. doi:10.1148/ radiol.2020200230

13. Xie J, Covassin N, Fan Z, et al. Association between hypoxemia and mortality in patients with COVID-19. Mayo Clin Proc. 2020;95 (6):1138-1147. doi:10.1016/j.mayocp.2020.04.006

14. Richardson S, Hirsch JS, Narasimhan M, et al. Presenting characteristics, comorbidities, and outcomes among 5700. patients hospitalized with COVID-19 in the New York City area. JAMA. 2020;323(20):2052-2059. doi:10.1001/jama.2020.6775

15. Agarwal N, Biswas B, Lohani P. Epidemiological determinants of COVID-19 infection and mortality: a study among patients presenting with severe acute respiratory illness during the pandemic in Bihar, India. Niger Postgrad Med J. 2020;27(4):293-301. doi:10.4103/npmj.npmj_301_20

16. Putri C, Hariyanto TI, Hananto JE, et al. Parkinson's disease may worsen outcomes from coronavirus disease 2019 (COVID-19) pneumonia in hospitalized patients: a systematic review, meta-analysis, and meta-regression. Parkinsonism Relat Disord. 2021;87:155-161. doi:10.1016/j. parkreldis.2021.04.019

17. Hariyanto TI, Putri C, Situmeang RFV, Kurniawan A. Dementia is a predictor for mortality outcome from coronavirus disease 2019 (COVID-19) infection. Eur Arch Psychiatry Clin Neurosci. 2021;271(2):393-395. PMID: 33104903; PMCID: PMC7586198. doi:10.1007/s00406-020-01205-z 
18. Hariyanto T, Japar K, Kwenandar F, et al. Inflammatory and hematologic markers as predictors of severe outcomes in COVID-19 infection: a systematic review and meta-analysis. Am J Emerg Med. 2021;41:110-119. PMID: 33418211; PMCID: PMC7831442. doi:10.1016/j. ajem.2020.12.076

19. Acharya D, Lee K, Lee DS, Lee YS, Moon SS. Mortality rate and predictors of mortality in hospitalized COVID-19 patients with diabetes. Healthcare. 2020;8(3):338. doi:10.3390/healthcare8030338

20. Ciceri F, Castagna A, Rovere-Querini P, et al. Early predictors of clinical outcomes of COVID-19 outbreak in Milan, Italy. Clinical Immunol. 2020;217:108509. doi:10.1016/j.clim.2020.108509

21. Jin JM, Bai P, He W, et al. Gender differences in patients with COVID-19: focus on severity and mortality. Front Public Health. $2020 ; 8: 152$. doi:10.3389/fpubh.2020.00152

22. Apea VJ, Wan YI, Dhairyawan R, et al. Ethnicity and outcomes in patients hospitalised with COVID-19 infection in East London: an observational cohort study. BMJ open. 2021;11(1):042140. doi:10.1136/bmjopen-2020-042140

23. GMI. Saudi-Arabia-Population-2019; 2019. Available from: https://www.globalmediainsight.com/blog/wp-content/uploads/Saudi-ArabiaPopulation-2019.jpg. Accessed February 1, 2022.

24. Shabrawishi M, Al-Gethamy M, Naser A, et al. Clinical, radiological and therapeutic characteristics of patients with COVID-19 in Saudi Arabia. PLoS One. 2020;15(8):0237130. doi:10.1371/journal.pone.0237130

25. Pagnesi M, Baldetti L, Beneduce A, et al. Pulmonary hypertension, and right ventricular involvement in hospitalised patients with COVID-19. Heart. 2020;106(17):1324-1331. doi:10.1136/heartjnl-2020-317355

26. Turgutalp K, Ozturk S, Arici M, et al. Determinants of mortality in a large group of hemodialysis patients hospitalized for COVID-19. BMC Nephrol. 2021;22(1):1. doi:10.1186/s12882-021-02233-0

27. Borah P, Mirgh S, Sharma SK, et al. Effect of age, comorbidity and remission status on outcome of COVID-19 in patients with hematological malignancies. Blood Cells Mol Dis. 2021;87:102525. doi:10.1016/j.bcmd.2020.102525

28. Gok M, Cetinkaya H, Kandemir T, et al. Chronic kidney disease predicts poor outcomes of COVID-19 patients. Int Urol Nephrol. 2021;4:1-8.

29. Al Dawish M, Robert A, Braham R, et al. Diabetes mellitus in Saudi Arabia: a review of the recent literature. Curr Diabetes Rev. 2016;12 (4):359-368. PMID: 26206092. doi:10.2174/1573399811666150724095130

30. Aldiab A, Shubair MM, Al-Zahrani JM, et al. Prevalence of hypertension and prehypertension and its associated cardioembolic risk factors; a population based cross-sectional study in Alkharj, Saudi Arabia. BMC Public Health. 2018;18(1):1327. doi:10.1186/s12889-018-6216-9

31. Chen N, Zhou M, Dong X, et al. Epidemiological and clinical characteristics of 99 cases of 2019 novel coronavirus pneumonia in Wuhan, China: a descriptive study. lancet. 2020;395(10223):507-513. doi:10.1016/S0140-6736(20)30211-7

32. Cummings MJ, Baldwin MR, Abrams D, et al. Epidemiology, clinical course, and outcomes of critically ill adults with COVID-19 in New York City: a prospective cohort study. Lancet. 2020;395(10239):1763-1770. doi:10.1016/S0140-6736(20)31189-2

33. Shi C, Wang L, Ye J, et al. Predictors of mortality in patients with coronavirus disease 2019: a systematic review and meta-analysis. BMC Infect Dis. 2021;21(1):663. doi:10.1186/s12879-021-06369-0

34. Blanco-Melo D, Nilsson-Payant BE, Liu WC, et al. Imbalanced host response to SARS-CoV-2 drives development of COVID-19. Cell. 2020;181 (5):1036-1045. doi:10.1016/j.cell.2020.04.026

35. Hariyanto TI, Japar KV, Damay V, et al. The use of ACE inhibitor/ARB in SARS-CoV-2 patients: a comprehensive narrative review. Asian J Med Sci. 2020;11(6):113-120. doi:10.3126/ajms.v11i6.29911

36. Klang E, Kassim G, Soffer S, et al. Severe obesity as an independent risk factor for COVID-19 mortality in hospitalized patients younger than 50 . Obesity. 2020;28(9):1595-1599. doi:10.1002/oby.22913

37. Lamure S, Duléry R, Di Blasi R, et al. Determinants of outcome in Covid-19 hospitalized patients with lymphoma: a retrospective multicentric cohort study. EClinicalMedicine. 2020;27:100549. doi:10.1016/j.eclinm.2020.100549

38. Knight SR, Ho A, Pius R, et al. Risk stratification of patients admitted to hospital with covid-19 using the ISARIC WHO clinical characterisation protocol: development and validation of the 4C mortality score. BMJ. 2020;9:370.

39. Guan W, Liang W, Zhao Y, et al. Comorbidity and its impact on 1590 patients with Covid-19 in China: a nationwide analysis. Eur Respir J. 2020;55 (5):2000547. doi:10.1183/13993003.00547-2020

40. Zhou F, Yu T, Du R, et al. Clinical course and risk factors for mortality of adult inpatients with COVID-19 in Wuhan, China: a retrospective cohort study. Lancet. 2020;395(10229):1054-1062. doi:10.1016/S0140-6736(20)30566-3

41. Di Castelnuovo A, Costanzo S, Antinori A, et al. RAAS inhibitors are not associated with mortality in COVID-19 patients: findings from an observational multicenter study in Italy and a meta-analysis of 19 studies. Vascul Pharmacol. 2020;135:106805. doi:10.1016/j.vph.2020.106805

42. Vaduganathan M, Vardeny O, Michel T, McMurray J, Pfeffer M, Solomon SD. Renin-Angiotensin-Aldosterone system inhibitors in patients with Covid-19. N Engl J Med. 2020;382(17):1653-1659. doi:10.1056/NEJMsr2005760

43. Wang W, Zhao X, Wei W, et al. Angiotensin-converting enzyme inhibitors (ACEI) or angiotensin receptor blockers (ARBs) may be safe for COVID-19 patients. BMC Infect Dis. 2021;21(114). doi:10.1186/s12879-021-05821-5

44. Memish ZA, El Bcheraoui C, Tuffaha M, et al. Obesity and associated factors-Kingdom of Saudi Arabia, 2013. Prev Chronic Dis. $2014 ; 11:$ E174. doi:10.5888/pcd11.140236

45. Burchfield J. Renin-Angiotensin-Aldosterone system: double-edged sword in COVID-19 infection; 2020.

46. Fu L, Wang B, Yuan T, et al. Clinical characteristics of coronavirus disease 2019 (COVID-19) in China: a systematic review and meta-analysis. $J$ Infect. 2020;80(6):656-665. doi:10.1016/j.jinf.2020.03.041

47. Di Castelnuovo A, Bonaccio M, Costanzo S, et al. Common cardiovascular risk factors and in-hospital mortality in 3894 patients with COVID-19: survival analysis and machine learning-based findings from the multicentre Italian CORIST Study. Nutr Metab Cardiovasc Dis. 2020;30 (11):1899-1913. doi:10.1016/j.numecd.2020.07.031

48. Undurraga Fourcade EA, Chowell G, Mizumoto K. COVID-19 case fatality risk by age and gender in a high testing setting in Latin America: Chile; March-August 2020.

49. Yang W, Kandula S, Huynh M, et al. Estimating the infection-fatality risk of SARS-CoV-2 in New York City during the spring 2020 pandemic wave: a model-based analysis. Lancet Infect Dis. 2021;21(2):203-212. doi:10.1016/S1473-3099(20)30769-6

50. Lim ZJ, Subramaniam A, Ponnapa Reddy M, et al. Case fatality rates for patients with COVID-19 requiring invasive mechanical ventilation. A meta-analysis. Am, J Respir Crit. 2021;203(1):54-66. doi:10.1164/rccm.202006-2405OC 
51. Barron E, Bakhai C, Kar P, et al. Associations of type 1 and type 2 diabetes with COVID-19-related mortality in England: a whole-population study. Lancet Diabetes Endocrinol. 2020;8(10):813-822. doi:10.1016/S2213-8587(20)30272-2

52. World Health Organization. Second round of the national pulse survey on continuity of essential health services during the COVID-19 pandemic: January-March 2021: interim report; April 22, 2021.

53. Di Gennaro F, Gualano G, Timelli L, et al. Increase in tuberculosis diagnostic delay during first wave of the COVID-19 pandemic: data from an Italian infectious disease referral hospital. Antibiotics. 2021;10(3):272. doi:10.3390/antibiotics10030272

\section{Publish your work in this journal}

The International Journal of General Medicine is an international, peer-reviewed open-access journal that focuses on general and internal medicine, pathogenesis, epidemiology, diagnosis, monitoring and treatment protocols. The journal is characterized by the rapid reporting of reviews, original research and clinical studies across all disease areas. The manuscript management system is completely online and includes a very quick and fair peer-review system, which is all easy to use. Visit http://www.dovepress.com/testimonials.php to read real quotes from published authors.

Submit your manuscript here: https://www.dovepress.com/international-journal-of-general-medicine-journal 